\title{
The effects of hygroscopicity on ice nucleation of fossil fuel combustion aerosols in mixed-phase clouds
}

\author{
Y. Yun ${ }^{1,2}$, J. E. Penner ${ }^{1}$, and O. Popovicheva ${ }^{3}$ \\ ${ }^{1}$ Department of Atmospheric, Oceanic, and Space Sciences, University of Michigan, Ann Arbor, MI 48105, USA \\ ${ }^{2}$ Atmospheric and Oceanic Sciences Program, Princeton University/Geophysical Fluid Dynamics Laboratory, 201 Forrestal \\ Road, Princeton, NJ 08540, USA \\ ${ }^{3}$ D.V. Skobeltsyn Institute of Nuclear Physics, M.V. Lomonosov Moscow State University, Moscow 119234, Russia
}

Correspondence to: Y. Yun (yuxingy@umich.edu)

Received: 8 July 2012 - Published in Atmos. Chem. Phys. Discuss.: 9 August 2012

Revised: 15 January 2013 - Accepted: 18 March 2013 - Published: 26 April 2013

\begin{abstract}
Fossil fuel black carbon and organic matter (ffBC/OM) are often emitted together with sulfate, which coats the surface of these particles and changes their hygroscopicity. Observational studies at cirrus temperatures $\left(\approx-40^{\circ} \mathrm{C}\right)$ show that the hygroscopicity of soot particles can modulate their ice nucleation ability. Here, we implement a scheme for 3 categories of soot (hydrophobic, hydrophilic and hygroscopic) on the basis of laboratory data and specify their ability to act as ice nuclei at mixed-phase temperatures by extrapolating the observations using a published deposition/condensation/immersion freezing parameterization. The new scheme results in significant changes to anthropogenic forcing in mixed-phase clouds. The net forcing in our offline model studies varies from 0.111 to $1.059 \mathrm{~W} \mathrm{~m}^{-2}$ depending on the ice nucleation capability of hygroscopic soot particles. The total anthropogenic cloud forcing and whole-sky forcing with the new scheme are $0.06 \mathrm{~W} \mathrm{~m}^{-2}$ and $-2.45 \mathrm{~W} \mathrm{~m}^{-2}$, respectively, but could be more positive (by about $1.17 \mathrm{~W} \mathrm{~m}^{-2}$ ) if hygroscopic soot particles are allowed to nucleate ice particles. The change in liquid water path dominates the anthropogenic forcing in mixed-phase clouds.
\end{abstract}

\section{Introduction}

Soot aerosols produced by incomplete combustion of fossil fuel and biomass containing black carbon (BC) and organic matter (OM) can absorb solar radiation, thereby changing vertical temperature profiles and decreasing surface radiation (Andreae and Gelencsér, 2006). Combustion aerosols can also act as cloud condensation nuclei, causing indirect effects on clouds by decreasing the cloud droplet radius. This causes cooling which counteracts the warming by greenhouse gases. Combustion aerosols can also act as heterogeneous ice nuclei (IN) in mixed-phase clouds (e.g. Cozic et al., 2008), as well as in cirrus clouds (Koehler et al., 2009; Penner et al., 2009). Recent measurements of IN activity at $-30^{\circ} \mathrm{C}$ and above water saturation for biomass-burning-generated particles show that IN number concentrations are elevated by at least a factor of 2-3 during biomass-burning episodes over those typical of background air (Prenni et al., 2012). The ice nucleation effects of fossil fuel combustion aerosols in mixed-phase clouds are very uncertain, which hinders the prediction of climate change. Due to the abundance of fossil fuel (ff) combustion aerosols, a small change in their ice nucleation ability can produce a large difference in indirect effects. Several studies have noted the sensitivity of aerosol forcing to ice nucleation in mixed-phase clouds (Lohmann and Hoose, 2009; Storelvmo et al., 2008a, 2011; Yun and Penner, 2012).

During the lifetime of soot aerosols in the atmosphere their hygroscopicity can be altered through coating by sulfate and organics (Zhang et al., 2008; Petters and Kreidenweis, 2007; Gunthe et al., 2011). Several laboratory experiments have investigated the effect of coating on the ability of soot particles to nucleate ice (DeMott et al., 1999; Mohler et al., 2005; Friedman et al., 2011; Crawford et al., 2011). DeMott et al. (1999) conducted ice nucleation experiments on lamp black soot at 213-233 K with sulfuric acid coating varying from zero to several weight percent. It was 
found that ice nucleation required the highest supersaturation at almost every temperature when the soot particle was treated with approximately one monolayer of sulfuric acid. However, the critical supersaturation required for ice formation was much lower when $\mathrm{BC}$ particles were treated with a multilayer equivalent coverage of sulfuric acid. Mohler et al. (2005) investigated ice nucleation of soot particles generated from a graphite spark generator (GSG) at 185-240 K, and found that internal mixtures of soot and sulfuric acid required higher supersaturation than that of uncoated soot to nucleate ice. The uncoated lamp black soot used by DeMott et al. (1999) and the GSG soot used by Mohler et al. (2005) have very different ice nucleation properties, with the uncoated GSG soot being a much more efficient ice nuclei (Kärcher et al., 2007). Friedman et al. (2011) found no heterogeneous ice nucleation below water saturation above their experimental detection limit (which was about $0.01-0.1 \%$ of the soot particle concentration, or about $10 \mathrm{~L}^{-1}$ ) for both coated and uncoated soot particles generated from a miniCAST Real Soot Generator at 253K and $243 \mathrm{~K}$. Above water saturation, ice nucleation could have occurred for both coated and uncoated soot but could not be distinguished from droplet formation. Crawford et al. (2011) examined nucleation of ice at $210-235 \mathrm{~K}$ for sulfuric-acid-coated soot particles generated from a CAST propane burner with various amounts of organic content. They found that uncoated soot particles with $30 \%$ organic mass content freeze before water saturation, and those with $80 \%$ and $90 \%$ organic mass content are inactive or freeze at water saturation, respectively. After coating by sulfuric acid, they all nucleated ice close to the homogeneous freezing conditions of sulphuric acid. These studies all lead to different conclusions about the effect of adding a soluble coating to soot. One possible reason for the differences in nucleation is the differences in the properties of the bare soot particles, for example, the organic content, porosity, surface area, etc. The amounts of sulfuric acid coating were also not quantified in most of these laboratory studies. This hinders the comparability among different laboratory studies, and also the applicability of the results to modeling studies. Nevertheless, these studies demonstrated that the addition of a soluble coating can alter the ice nucleation ability of soot particles, which most model studies of aerosol indirect effects (AIE) do not explicitly consider (e.g. Yun and Penner, 2012; Lohmann and Hoose, 2009; Storelvmo et al., 2011).

Here we adopt recent laboratory studies from Popovicheva et al. (2008b, 2010, 2011) and Koehler et al. (2009), which provide a link between sulfuric acid coating, hygroscopicity, and ice nucleation efficiencies, and develop a method of differentiating hydrophobic, hydrophilic, and hygroscopic particles and their ice nucleation in models. Coating or mixing with secondary organic matter may also change the particle hygroscopicity as was shown in laboratory simulations performed in Popovicheva et al. (2009) and Crawford et al. (2011), among others. However, it has been shown by
Popovicheva et al. (2009) that with the same amount of coverage, the impact of organic acid on soot hygroscopicity is weaker than that from sulfuric acid. Also, our model currently does not follow organic functional groups. To do so would require a sophisticated organic chemistry/aerosol model that accounts for formation of secondary organic aerosols (as in, for example, Lin et al., 2012) as well as a better quantification of the role of different organic functional groups in ice formation. Thus, this study, which only considers the coating of soot by sulfuric acid, should be viewed as an exploratory step toward a more sophisticated treatment of ice nucleation.

Progress in characterizing soot hygroscopicity has been achieved by a systematic comparative analysis of the water uptake by soot particles of various physico-chemical properties and by the identification of water-soot interaction mechanisms in relation to the soot composition (Popovicheva et al., 2008a). Two mechanisms of water-soot interaction, namely, the bulk dissolution of water onto soot due to coverage by soluble compounds and the water molecule adsorption on surface active sites, were identified. The formation of a water film that extended over the surface at a relative humidity $<80 \%$ was suggested as a quantification measure to separate soots with respect to their hygroscopicity (Popovicheva et al., 2008b). Hydrophobic soot which has a limited number of active sites never forms a film, while hydrophilic soot develops a water film on its oxidized surface. Water uptake on hygroscopic soot covered by soluble compounds is characterized by many layers of water uptake. Koehler et al. (2009) performed a series of experiments on well-characterized soot and linked the extent of soot hygroscopicity to its IN ability, based on Popovicheva et al. (2008b). The frozen fractions of hydrophobic, hydrophilic, and hygroscopic soot were measured at cirrus cloud temperatures $\left(\approx-40^{\circ} \mathrm{C}\right.$ or less $)$. In addition, Popovicheva et al. (2011) performed a series of laboratory experiments to identify the threshold amount of sulfate coating needed to transform hydrophobic to hydrophilic to hygroscopic soot.

Here we develop a method of differentiating hydrophobic, hydrophilic, and hygroscopic soot particles by the amount of sulfate deposited on the particles and treat their respective ice-nucleating properties in mixed-phase clouds in a model. The mixed-phase cloud treatment for hydrophobic, hydrophilic, and hygroscopic soot is developed by extending the observations by Koehler et al. (2009) to mixed-phase cloud temperatures using the Phillips et al. (2008) parameterization. Section 2 describes the 3 -ffBC/OM (hydrophobic, hydrophilic and hygroscopic) soot scheme, which is implemented in place of a single-category scheme (1-ffBC/OM) (Wang et al., 2009) as well as our method of extending the Koehler et al. (2009) observations using the Phillips et al. (2008) parameterization. In section 3, we present the hydrophobic, hydrophilic and hygroscopic ffBC/OM aerosol fields, as well as the cloud water field and radiative forcing from the original and the new scheme. Section 3 also 
presents an updated total anthropogenic forcing with the new 3-ffBC/OM scheme. A discussion follows in Sect. 4.

\section{Methods}

The 3-ffBC/OM scheme was implemented into the CAMIMPACT coupled aerosol transport model and general circulation model (Wang and Penner, 2010), as well as an offline radiation model. The coupled model (online simulation) provides the aerosol fields and meteorology fields for the offline model and is used to calculate the total anthropogenic forcing. The offline model reads the aerosol and meteorology fields and examines the cloud water fields and mixed-phase cloud anthropogenic forcing. Using the offline model ensures that a fixed amount of ffBC/OM aerosol enters the ice nucleation scheme, and that changes in the cloud field and radiation is solely from the treatment of hygroscopicity in the ice nucleation scheme.

\subsection{Models}

The University of Michigan IMPACT aerosol model has a detailed description of the formation of sulfate particles, their interaction with non-sulfate aerosols, dry deposition, and wet deposition (Herzog et al., 2004; Liu et al., 2005, Wang et al 2009). Pure sulfate aerosols are predicted to be in one of three modes (nucleation mode (radius $<5 \mathrm{~nm}$ ), Aitken mode $(5 \mathrm{~nm}<$ radius $<50 \mathrm{~nm}$ ), and accumulation mode (radius $>50 \mathrm{~nm})$ ). Both the mass and number of pure sulfate aerosol for the three modes are predicted. The primary nonsulfate aerosol components included in the model are natural organic matter (NOM), fossil-fuel-burning black carbon and organic matter (ffBC/OM), biomass-burning black carbon and organic matter (bbBC/OM), aircraft $\mathrm{BC}(\mathrm{ABC})$, dust, and sea salt. Only the mass concentration is predicted for these non-sulfate aerosols although dust and sea salt are carried in 4 separate size bins. The number concentrations of these non-sulfate aerosols are calculated with assumed size distributions. Although BC and OM from fossil fuel burning and biomass burning are treated as distinct species in the model, they are assumed to be internally mixed (Liu et al., 2005). Carbonaceous aerosol (OM and BC) is currently represented by a single submicron size bin, which is the sum of three log-normal distributions with the geometric means and variances described in Penner et al. (1998). For fossil fuel $\mathrm{BC}$ and $\mathrm{OM}$, the volume mean radius is 0.103 mum. Comparisons of the model-simulated BC profiles to data from Schwarz et al. (2008) were included in Koch et al. (2009). The mixing of sulfate with non-sulfate aerosols occurs through condensation of sulfuric acid onto the surface of non-sulfate aerosols, coagulation with pure sulfate aerosols, as well as aqueous formation of sulfuric acid in cloud droplets. The coated sulfate mass on each separate type of non-sulfate aerosol is separately predicted. Detailed descriptions of the aerosol microphysics can be found in Herzog et al. (2004).

The NCAR CAM3 model was updated to include a two-moment microphysics scheme for cloud liquid and ice (Wang and Penner, 2010). In mixed-phase clouds, the Phillips et al. (2008) parameterization (PH08) of deposition/condensation/immersion freezing was implemented (Yun and Penner, 2012). Phillips et al. (2008) has been updated to suppress deposition/condensation/immersion freezing by soot above $-15^{\circ} \mathrm{C}$ (Phillips et al., 2013). We have compared the current parameterization with the revised Phillips et al. (2013) parameterization for soot aerosols, and found that the changes of ice number concentrations simulated in our model between the old and new versions of parameterization are generally within $10 \%$. The ice number concentration is lower with the new parameterization at warm temperature regions due to the suppression of soot ice nucleation. It is higher at cold temperature regions (where soot ice nucleation is not suppressed) due to the smaller baseline value of soot surface area. Comparison plots are shown in appendix A).The contact freezing parameterization is that of Young (1974), with the contact ice nuclei concentration fitted to that recommended by Young (1974). All aerosols are assumed to be interstitial for the calculation of ice nucleation in our model. In reality, particles might have entered the droplets either due to higher peak supersaturations at cloud base or due to collision scavenging, in which case the effect of hygroscopicity on ice nucleation may be overruled. However, we have estimated the fraction of hydrophobic and hydrophilic soot activated into cloud droplet to be about $15 \%$ in our model. That from hygroscopic soot is about $20 \%$. From the estimate by Hoose et al. (2008), the contribution of collision scavenging is at most about one-fifth of nucleation scavenging for $\mathrm{BC}$ and $\mathrm{OM}$. Therefore, the effect of hygroscopicity still matters for the rest (about $80 \%$ ) of the soot particles.

The offline radiation model of Chen and Penner (2005) was extended to include mixed-phase clouds. The ice nucleation scheme in mixed-phase clouds is the same as that in the CAM-IMPACT model (Yun and Penner, 2012). In the offline radiation model, we predict the ice number concentration from nucleation using aerosol concentrations from an online calculation that are read-in. The ice/liquid number/mass concentration change from contact freezing and the Bergeron-Findeisen process (the conversion of liquid to ice) was also implemented, due to its importance to radiative forcing (Storelvmo et al., 2008b). Other meteorology variables are fixed and no further processing of ice particles takes place (no sedimentation, coagulation, or precipitation formation).

\subsection{3-ffBC/OM scheme}

The differentiation between hydrophobic, hydrophilic, and hygroscopic $\mathrm{ffBC} / \mathrm{OM}$ aerosols is based on the number of monolayers of sulfuric acid coating. Freshly emitted ffBC/OM particles are assumed to be hydrophobic. After 


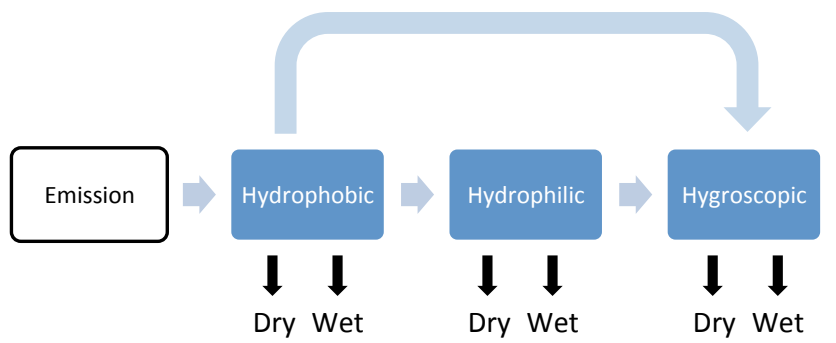

Fig. 1. Diagram showing the 3-ffBC/OM scheme. Hydrophobic, hydrophilic and hygroscopic BM/OM then enter into the ice nucleation scheme in mixed-phase clouds as shown in Fig. 2.

each time step, the number of monolayers of sulfate coating $\left(n_{\text {coat }}\right)$ is calculated and compared with threshold values. If $n_{\text {coat }}<1$, the particle remains hydrophobic. If $1 \leq n_{\text {coat }}<3$, the particle is moved to the hydrophilic category. If $n_{\text {coat }} \geq 3$, the particle become hygroscopic. This is shown as a diagram in Fig. 1. The size distributions of the three ffBC/OM species prior to coating by sulfate (and water) are assumed fixed (see Penner et al., 1998). The accommodation coefficient for the condensation of sulfuric acid on hydrophobic and hydrophilic particles is set to 0.018 (Zhang and Zhang, 2005), while that for hygroscopic particles is 0.65 , similar to sulfuric acid surfaces (Pöschl et al., 1998).

The PH08 parameterization was modified to treat the nucleation of ice in mixed-phase clouds by the $3-\mathrm{ffBC} / \mathrm{OM}$ categories. Ice nucleation was measured at $-40^{\circ} \mathrm{C}$ as well as at a colder temperature $\left(-51.5^{\circ} \mathrm{C}\right.$ or $\left.-57^{\circ} \mathrm{C}\right)$ in Koehler et al. (2009). Due to the coexistence of liquid and ice, water saturation is assumed in mixed-phase clouds in our model. Therefore, we use the frozen fraction measured at $-40{ }^{\circ} \mathrm{C}$ at water saturation to adjust the $\mathrm{PH} 08$ parameterization in mixed-phase clouds. The uncertainty of the relative humidity w.r.t. water in Continuous Flow Diffusion Chamber (CFDC) is about $3 \%$ (P. R. DeMott, personal communication, 2012). This is an implicit artifact of detecting IN using any CFDC type device or any ice nucleation device presently available (P. R. DeMott, personal communication, 2012). By using the published value of the fraction of soot nucleated at $100 \% \pm 3 \%$ RHw we are assuming that the measured values represent the averaged value from $97 \%$ to $103 \%$ RHw. The data published by Koehler et al. (2009) show that the true fractions could be higher or lower by approximately \pm 10 if the measured RHw differs by $3 \%$.

All of the soot samples used in Koehler (2009) studies were first characterized using three hygroscopicity categories, using the concept of quantification of water uptake (Popovicheva et al., 2008b). There are five different soot samples. Aircraft engine combustor (AEC) soot is the only soot sample characterized as hygroscopic, so it was chosen as the representative for hygroscopic soot in our study. Thermal soot (TS) is hydrophobic. Graphitized thermal soot (GTS) is produced by heating the TS soot to $\sim 3000^{\circ} \mathrm{C}$ to
Table 1. Offline simulations.

\begin{tabular}{ll}
\hline Schemes & Description \\
\hline 1BC & 1-ffBC/OM scheme \\
3BC_SCO & $\begin{array}{l}\text { 3-ffBC/OM scheme and hygroscopic soot } \\
\text { particles as heterogeneous ice nuclei }\end{array}$ \\
3BC_noSCO & $\begin{array}{l}\text { 3-ffBC/OM scheme and no hygroscopic } \\
\text { soot particles as heterogeneous ice nuclei }\end{array}$ \\
\end{tabular}

remove any impurities from the surface and graphitize the structure, and it is extremely hydrophobic. We think that the soot emitted from fossil fuel combustion is likely to have impurities and unlikely to be extremely hydrophobic. Therefore TS was selected as the representative for hydrophobic soot for this study. Thermal oxidized soot (TOS) and TC1 soot (TC1 kerosene flame soot) are both characterized as hydrophilic. However, TC1 soot is typically composed of agglomerates of $20-50 \mathrm{~nm}$ particles, is highly microporous and is subject to swelling phenomenon. Therefore the hydrophilic properties of TC1 soot may not be solely explained by the surface properties. So TOS was selected as the representative for hydrophilic soot for this study. For hydrophobic and hydrophilic soot, we use the data for the $200 \mathrm{~nm}$ particles because this size is close to the volume mean diameter of the $\mathrm{BC} / \mathrm{OM}$ particles in our model, which is $180 \mathrm{~nm}$. There are only data for polydisperse particles at $-40^{\circ} \mathrm{C}$ for hygroscopic soot. However, the frozen fractions of the polydisperse particles and $250 \mathrm{~nm}$ particles are similar at $-57^{\circ} \mathrm{C}$. So we assumed that differences between the size distribution between the polydisperse particles and our soot particles would not have a large impact on the freezing properties of hygroscopic particles. The frozen fraction of hydrophobic, hydrophilic, and hygroscopic soot measured at $-40^{\circ} \mathrm{C}$ and at water saturation is $0.03 \%, 2 \%$, and $3 \%$, respectively (Table 1 in Koehler et al., 2009), while that predicted by PH08 for the same conditions is $0.2 \%$. Therefore, we increased the PH08 frozen fraction by a factor of 10 for hydrophilic $\mathrm{ffBC} / \mathrm{OM}$, and reduced it by a factor of 0.15 for hydrophobic ffBC/OM. In doing so, we preserve the temperature dependence specified in $\mathrm{PH} 08$.

For hydrophobic and hydrophilic soot, heterogeneous freezing is the likely freezing mechanism in the Koehler et al. (2009) experiments due to the monotonic increase of frozen fraction with $\mathrm{RHw}$, and the lack of correlation with the "Koop" line. Freezing for hygroscopic particles followed the Koop line for homogeneous freezing of pure dissolved solute at $-40^{\circ} \mathrm{C}$ for a short distance near water saturation. However, the frozen fraction slightly above water saturation was far smaller than that predicted by a homogeneous freezing mechanism. Therefore, we made two assumptions to treat the freezing of hygroscopic particles at higher temperatures. The first is that these particles freeze homogeneously, so we exclude them as a heterogeneous IN. This 


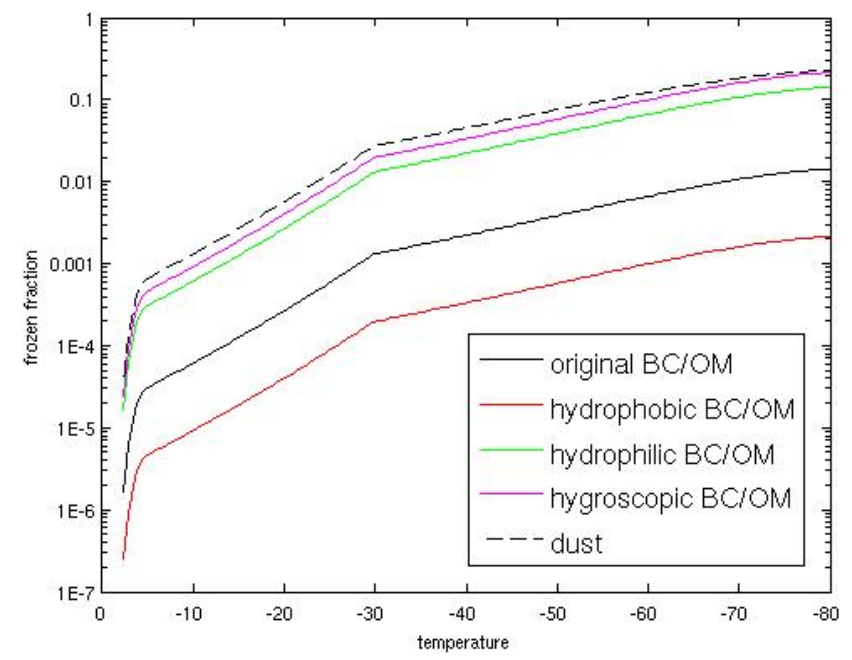

Fig. 2. Frozen fraction as a function of temperature for dust, $\mathrm{BC} / \mathrm{OM}$ in the original 1-ffBC/OM scheme, and hydrophobic, hydrophilic, and hygroscopic BC/OM in the new 3-ffBC/OM scheme with hygroscopic soot particles as heterogeneous ice nuclei.

Table 2. ffBC/OM burden and lifetime.

\begin{tabular}{lll}
\hline Schemes & Burden & Lifetime \\
\hline Hydrophobic & 0.0279 & 0.45 \\
Hydrophilic & 0.0396 & 0.95 \\
Hygroscopic & 0.157 & 4.55 \\
3-ffBC/OM Total & 0.225 & 3.68 \\
1-ffBC/OM Total & 0.233 & 3.88 \\
\hline
\end{tabular}

is similar to the observation of internally mixed propane burner soot by Crawford et al. (2011). The second is that they freeze heterogeneously, and we scale the frozen fraction of PH08 by a factor of 15 . This is similar to the observation of multilayer coated lamp black soot by DeMott et al. (1999). The ice nucleation ability as a function of temperature for dust, the $\mathrm{ffBC} / \mathrm{OM}$ in the original $1-\mathrm{ffBC} / \mathrm{OM}$ scheme, and hydrophobic, hydrophilic, and hygroscopic soot in the 3-ffBC/OM scheme with hygroscopic soot as heterogeneous ice nuclei are shown in Fig. 2. The contact freezing treatment was kept the same as in the 1-ffBC/OM scheme, since we want to examine the effect of treating soot ice nucleation using the results of Koehler et al. (2009), whose measurement includes deposition/condensation/immersion freezing but no contact freezing. Contact freezing in our model is represented by the Young (1974) parameterization fitted to the observation of total number of contact ice nuclei measured by Blanchard (1957) (see Yun and Penner, 2012). This treatment makes the contribution from contact freezing to total ice nucleation very small (on the order of $1 \%$ ). The cirrus cloud ice nucleation scheme was kept unchanged in this paper; this may be inconsistent, but we want to focus on the effect in mixed-phase clouds. (a) hydrophobic ffBC/OM mg/m2 (burden $2.79 \mathrm{e}-2 \mathrm{Tg}$ )

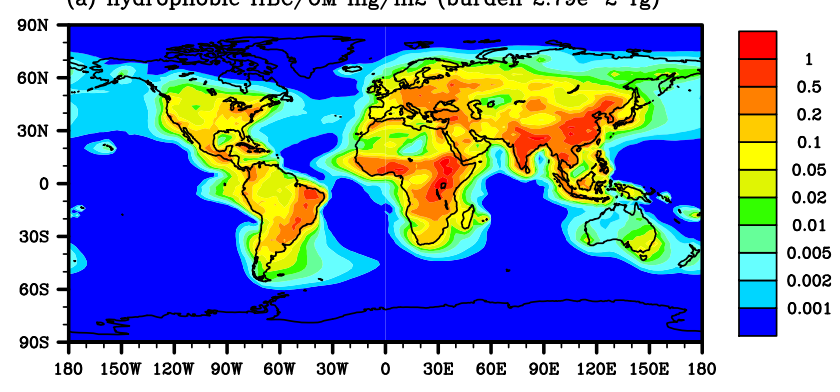

(b) hydrophilic ffBC/OM mg/m2 (burden $3.96 \mathrm{e}-2 \mathrm{Tg}$ )

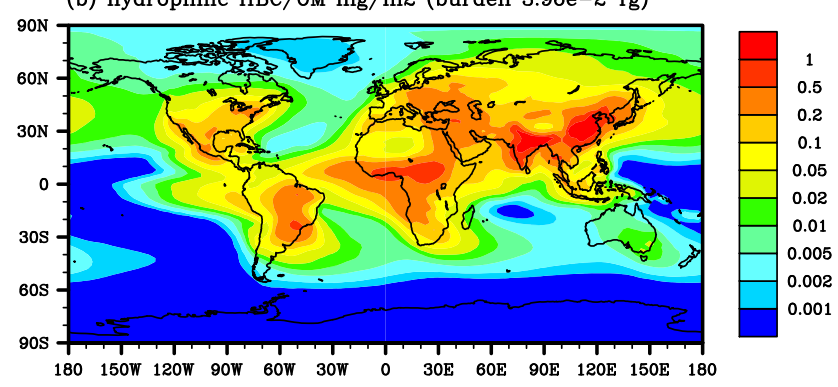

(c) hygroscopic ffBC/OM mg/m2 (burden $1.57 \mathrm{e}-1 \mathrm{Tg}$ )

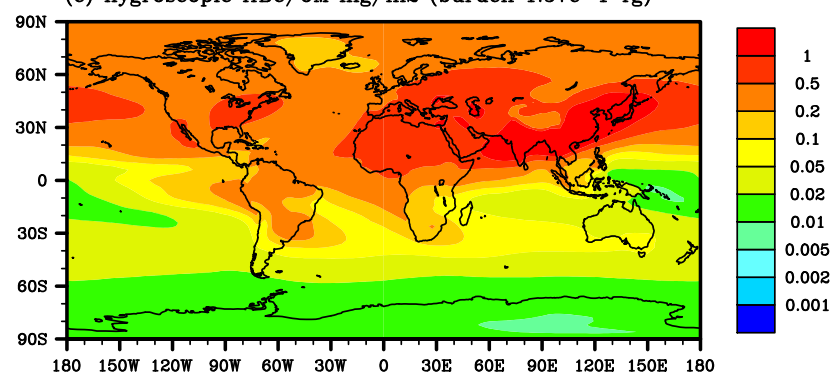

Fig. 3. PD annual average horizontal distribution of columnintegrated hydrophobic (a), hydrophilic (b), and hygroscopic (c) ffBC/OM $\left(\mathrm{mg} \mathrm{m}^{-2}\right)$.

\subsection{Experiment setup}

Table 1 shows the three offline simulations. In the 1BC simulation, the original PH08 scheme is used and the sum of hydrophobic, hydrophilic, and hygroscopic ffBC/OM is treated as one species. For each configuration, the model is run twice with present-day (PD) and pre-industrial (PI) aerosol fields. PI aerosol fields are only applied to ice nucleation in mixedphase clouds. The online model is run using the 3BC_noSCO scheme with PD and PI emission files described in Penner et al. (2009). Aerosol direct effects as well as indirect effects on warm-phase and cirrus clouds are included in the online model. 

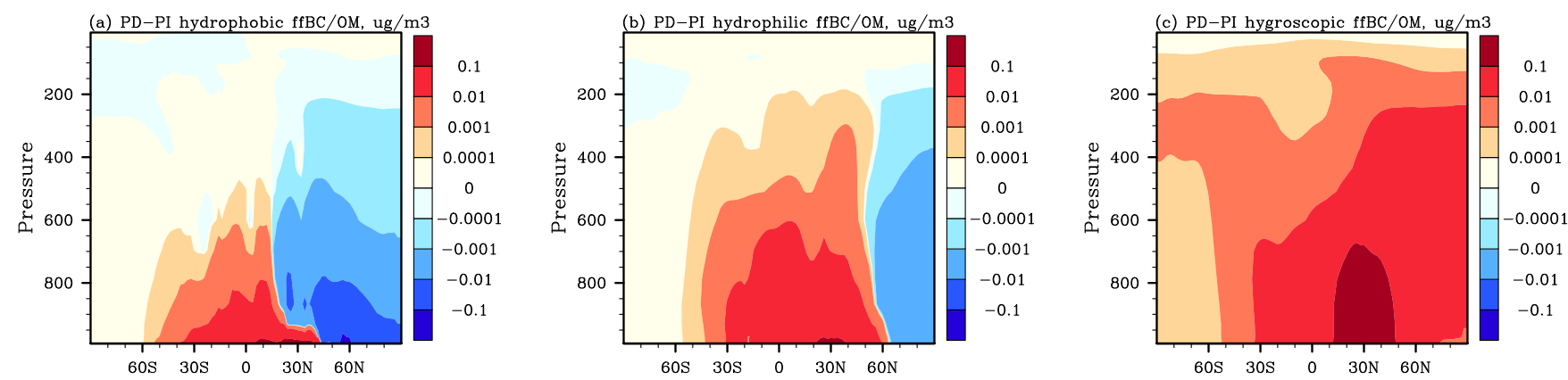

Fig. 4. PD-PI annual average changes of hydrophobic (a), hydrophilic (b), and hygroscopic (c) ffBC/OM $\left(\mu \mathrm{g} \mathrm{m}^{-3}\right)$.

\section{Results}

\subsection{Aerosol fields for hydrophobic, hydrophilic, and hygroscopic ffBC/OM}

Figure 3 shows the PD horizontal distribution of columnintegrated hydrophobic, hydrophilic and hygroscopic ffBC/OM. Hydrophobic ffBC/OM is confined mainly to regions near emissions. Hydrophilic ffBC/OM is transported farther than hydrophobic ffBC/OM. Hygroscopic ffBC/OM is even more widespread. Table 2 shows the burden and lifetime for hydrophobic, hydrophilic, and hygroscopic soot using the 3-ffBC/OM scheme and the 1-ffBC/OM scheme. The majority of the ffBC/OM particles are hygroscopic, contributing $69.93 \%$ to the total ffBC/OM burden. Hydrophilic and hydrophobic ffBC/OM particles contribute $17.64 \%$ and $12.43 \%$, respectively. The aging process that transforms hydrophobic soot to hydrophilic and hygroscopic soot as a result of additional increases in sulfate coating is considered as a sink of the hydrophobic and hydrophilic soot particles, while the only sink of hygroscopic soot is via wet and dry deposition. Therefore hydrophobic soot particles have the shortest lifetime of 0.45 days. The lifetimes of the hydrophilic and hygroscopic ffBC/OM particles are 0.95 and 4.55 days, respectively. The lifetime of soot particles using the $3-\mathrm{ffBC} / \mathrm{OM}$ scheme is decreased compared to that in the $1-\mathrm{ffBC} / \mathrm{OM}$ scheme. This is mainly driven by the increased wet removal rate for the hygroscopic particles, since the sulfate coating thickness is not diluted by newly emitted hydrophobic soot through the process of calculating an "averaged" coating thickness as in the 1-ffBC/OM scheme. As a result, the total fossil fuel combustion soot burden is smaller in the 3-ffBC/OM scheme (Table 2).

Figure 4 shows the change in the hydrophobic, hydrophilic, and hygroscopic ffBC/OM number concentrations from PI to PD due to anthropogenic emissions. Concentrations increase in most places due to higher PD emissions. However, the concentration of hydrophobic ffBC/OM is smaller for the PD in most places of the Northern Hemisphere (NH) (Fig. 4a), and the concentration of hydrophilic ffBC/OM is smaller for PD at NH high latitudes (Fig. 4b).
This is because sulfate emissions increase significantly in the PD in the industrial regions in the $\mathrm{NH}$ and more readily coat the surface of the ffBC/OM particles. Therefore, the ffBC/OM particles become hygroscopic more easily and are less likely to remain hydrophilic and even less likely to remain hydrophobic.

\subsection{Comparison of mixed-phase cloud water field and radiative forcing}

Figure 5 shows the grid-mean ice number concentration $\left(N_{i}\right)$ change from PI to PD in mixed-phase clouds using the offline model. There is a larger increase in $N_{i}$ in the NH than in the Southern Hemisphere (SH) for all three experiments. The $1 \mathrm{BC}$ case shows increases of the order of $1 \mathrm{~L}^{-1}$ throughout the mid-troposphere north of $30^{\circ} \mathrm{N}$, while the $3 \mathrm{BC}$ noSCO case shows decreases north of $60^{\circ} \mathrm{N}$, caused by the decrease of hydrophilic ffBC/OM (Fig. 4b). The 3BC_SCO case shows much larger increases that also extend to the $\mathrm{SH}$, due to the enhanced effect of hygroscopic ffBC/OM. In general, $N_{i}$ increases from PI to PD predicted by the 3 -ffBC/OM scheme are very different from those predicted by the 1ffBC/OM scheme. However, the sign of the change depends strongly on the freezing ability of hygroscopic ffBC/OM. When hygroscopic ffBC/OM acts as a heterogeneous IN in mixed-phase clouds, there is a larger increase in $N_{i}$; when hygroscopic ffBC/OM does not, there is a smaller overall increase.

An increase in $N_{i}$ causes a net conversion of liquid to ice mass in mixed-phase clouds, as a result of the BergeronFindeisen process. Figure 6 shows the change in the liquid water mass mixing ratio in all 3 schemes from PI to PD. Liquid cloud mass mixing ratio decreases at most latitudes except north of $60^{\circ} \mathrm{N}$ in the 3BC_noSCO scheme. The decrease is largest in the 3BC_SCO case and smallest in the 3BC-noSCO case, consistent with the changes in $N_{i}$.

Table 3 shows the anthropogenic forcing in mixed-phase clouds from the three cases. Two aspects contribute to the anthropogenic ffBC/OM forcing. The first is the decrease of ice effective radius associated with the increase of $N_{i}$ (Fig. 5). Smaller ice effective radius leads to more reflected 

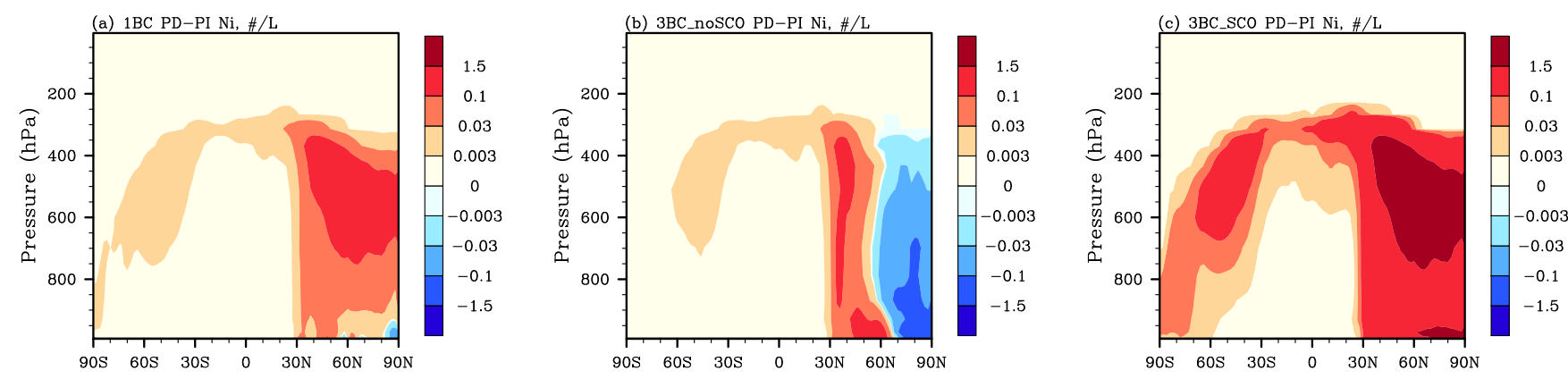

Fig. 5. PD-PI annual average changes of grid-mean ice number concentration in mixed-phase clouds from $1 \mathrm{BC}(\mathbf{a}), 3 \mathrm{BC} \_$noSCO (b) and 3BC_SCO (c) simulations $\left(\# \mathrm{~L}^{-1}\right)$.
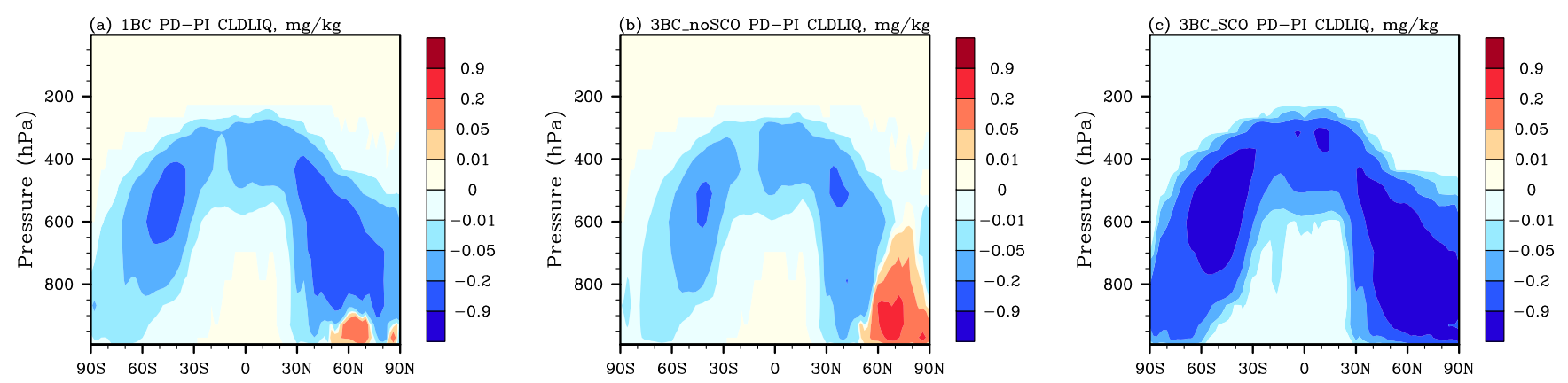

Fig. 6. PD-PI annual average changes of grid-mean liquid water mass mixing ratio (CLDLIQ) in mixed-phase clouds from 1BC (a), 3BC_noSCO (b) and 3BC_SCO (c) simulations $\left(\mathrm{mg} \mathrm{kg}^{-1}\right)$.

Table 3. Annual average anthropogenic cloud forcings (CF) and whole-sky forcings $\left(\mathrm{W} \mathrm{m}^{-2}\right)$. The line separates offline and online simulations. Offline forcings are for mixed-phase clouds, while online forcings include all effects: warm, mixed-phase, and cirrus clouds and direct effects.

\begin{tabular}{lllll}
\hline & SWCF & LWCF & Net CF & $\begin{array}{l}\text { Net Whole- } \\
\text { Sky }\end{array}$ \\
\hline 1BC & 0.188 & -0.0173 & 0.171 & 0.171 \\
3BC_SCO & 1.106 & -0.0470 & 1.059 & 1.059 \\
3BC_noSCO & 0.118 & -0.007 & 0.111 & 0.111 \\
\hline 3BC_noSCO & 2.28 & -2.22 & 0.06 & -2.45 \\
(online) & & & & \\
\hline
\end{tabular}

solar radiation and less long-wave transmission, reducing the net incoming short-wave radiation as well as the net outgoing long-wave radiation at the top-of-the-atmosphere (TOA). Therefore, the anthropogenic short-wave (SW) forcing from this effect is negative, and the long-wave (LW) forcing is positive. The second aspect is the decrease of liquid water mass mixing ratio (Fig. 6). This results in a smaller liquid water path in the present-day, and therefore a reduced short-wave reflectivity and increased long-wave transmissivity. The result of this change is a positive SW forcing and a negative
LW forcing. As shown in Table 3, the second effect dominates the sign of the SW and LW forcings.

The treatment of ffBC/OM with different freezing properties results in significant changes to the offline mixed-phase cloud forcing (CF). When hygroscopic ffBC/OM particles are excluded as IN, there is a $35 \%$ decrease in the net anthropogenic forcing compared to the $1 \mathrm{BC}$ case. When hygroscopic ffBC/OM particles are included, there is an increase by a factor of 6 , due to the large liquid water change in the 3BC_SCO case. The two treatments for hygroscopic soot particles lead to a net offline mixed-phase anthropogenic forcing that varies by almost a factor of 10 , from 0.111 to $1.059 \mathrm{~W} \mathrm{~m}^{-2}$.

The total anthropogenic forcing (including sulfate) using the $3 \mathrm{BC}$ scheme with the coupled model shows a positive net $\mathrm{CF}$ of $0.06 \mathrm{~W} \mathrm{~m}^{-2}$. The net whole-sky forcing is the same as the $\mathrm{CF}$ in the offline simulations because the aerosol and meteorology fields are fixed and no direct effect is included. That for the online model, however, includes all effects (e.g. nucleation of warm cloud, cirrus cloud, and direct effects as well as changes to the cloud fields that result from nucleation) and is $-2.45 \mathrm{~W} \mathrm{~m}^{-2}$. However, this number would be smaller if hygroscopic soot particles were allowed to act as IN in mixed-phase clouds in the online simulation. Based on a one-year simulation using the online model, the net 

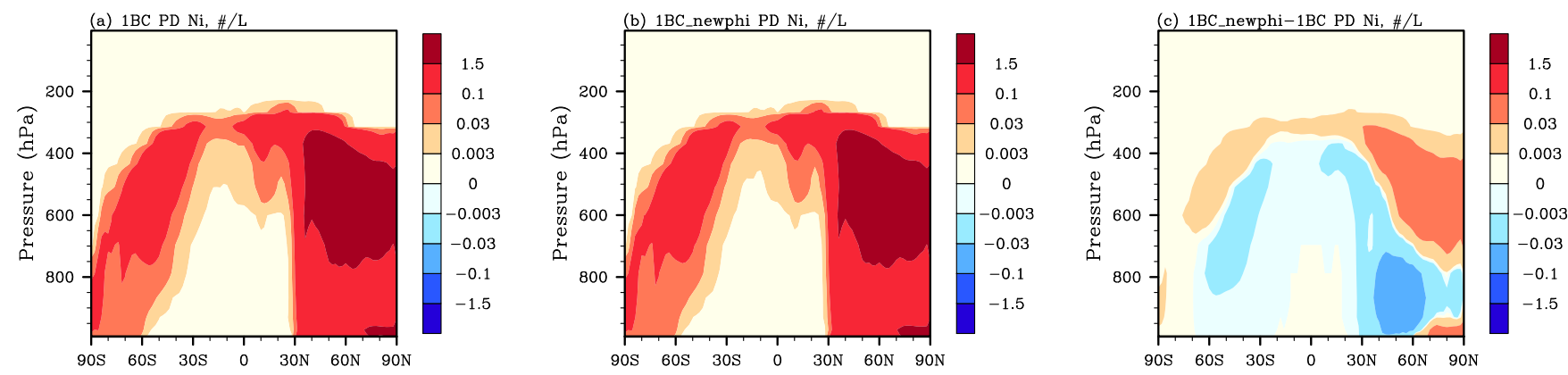

Fig. A1. Comparison of the simulated ice number concentration with (a) the original Phillips et al. (2008) scheme, (b) the new Phillips et al. (2013) schem, and (c) their differences.

whole-sky anthropogenic aerosol forcing for 3BC_SCO case is $-1.28 \mathrm{~W} \mathrm{~m}^{-2}$.

\section{Discussion}

Anthropogenic aerosol emissions are thought to produce negative forcing through their indirect effect on warm clouds. This could counteract the warming effect of greenhouse gases and thus has important implications for predicting climate change. However, there are large uncertainties associated with their effects in mixed-phase clouds, which hinders our ability to fully determine the effects of aerosols on climate. Our results show that the net effect of anthropogenic aerosols on mixed-phase clouds is a warming. This warming effect comes from the decrease of optical depth due to the Bergeron-Findeisen process. To estimate the importance of mixed-phase cloud forcing relative to other clouds, we removed the effect of the $\operatorname{ADE}\left(0.67 \mathrm{~W} \mathrm{~m}^{-2}\right.$ estimated using the offline radiation model) from the online anthropogenic SWCF to estimate the forcing from only the AIE $\left(1.61 \mathrm{~W} \mathrm{~m}^{-2}\right)$. As a result, the SW forcing in mixed-phase clouds contributes $\sim 7.33-68.7 \%$ of the anthropogenic SW forcing in all clouds, and the LW forcing contributes $\sim 0.32$ $2.12 \%$ (Table 3). The magnitude of the mixed-phase cloud forcing is very sensitive to whether the effect of hygroscopicity is considered, and how it is considered. It is larger when hygroscopic particles are included as IN due to the larger fraction of soot particles acting as ice nuclei. More laboratory experiments are needed to fully determine the freezing properties of hygroscopic ffBC/OM at mixed-phase cloud temperatures to reduce the range of uncertainty.

\section{Appendix A}

We have implemented the revised Phillips et al. (2013) parameterization for soot aerosols, and compared the simulated ice number concentration with the previous version with the
1-ffBC/OM scheme. Their differences are shown in the figure below. Figure A1a is the ice number concentration with the original Phillips et al. (2008) scheme. Figure A1b is the ice number concentration with the new Phillips et al. (2013) scheme. Figure A1c is their differences.

Immersion freezing by soot is suppressed at the warmest temperatures in the new Phillips et al. (2013) parameterization. No ice nucleation by soot is allowed at temperatures above $-15^{\circ} \mathrm{C}$. This reduces the contribution of soot IN, as shown in in Fig. A1c at middle and high latitudes where soot is present and the temperature is warm. Furthermore, $\alpha_{\mathrm{BC}}$, which is the fractional contribution of BC IN to total IN in the baseline condition in Phillips et al. $(2008,2013)$ parameterizations, is reduced by a factor $\Xi$ in the new parameterization due to the consideration of surface polarity and organic coatings. For our implementation of the Phillips et al. (2013) parameterization, we assume that for the "average" fossilfuel-burning soot in the 1 -ffBC/OM scheme there is some level of organic coating and surface polarity, and assume an average value of $\Xi=0.5$ ( $\alpha_{\mathrm{BC}}$ is reduced by a factor of 0.5 ). This will also lead to less predicted soot IN with the new parameterization. In addition, the baseline surface area of soot is reduced in Phillips et al. (2013). This causes an increase of the predicted soot IN since the predicted soot IN is based on the ratio of soot surface area at the grid point to the baseline value. So for cold temperature regions where soot is allowed to nucleate ice in both the old and new parameterizations, the contribution of soot IN is increased in Phillips et al. (2013) compared to Phillips et al. (2008). The changes of ice number concentrations between the old and new versions of parameterization are generally within $10 \%$.

Acknowledgements. J. E. P. and Y. Y. are grateful for support from US CRDF/NFS, NSF ATM 0609836, and DOE DE-FG02-97ER62370 and FG0201 ER63248. O. P. appreciates the financial support from projects CRDF-RFBR 2949 and RFBR 12-05-00395_a. R. Chen and L. Xu provided useful suggestions. We are grateful for computer time provided by the NCAR Computational Information Systems Laboratory. 
Edited by: K. Carslaw

\section{References}

Andreae, M. O. and Gelencsér, A.: Black carbon or brown carbon? The nature of light-absorbing carbonaceous aerosols, Atmos. Chem. Phys., 6, 3131-3148, doi:10.5194/acp-6-3131-2006, 2006.

Blanchard, D. C.: The supercooling, freezing and melting of giant waterdrops at terminal velocity in air, in Artificial Simulation of Rain, London, Pergamon Press, 233-249, 1957.

Chen, Y. and Penner, J. E.: Uncertainty analysis for estimates of the first indirect aerosol effect, Atmos. Chem. Phys., 5, 2935-2948, doi:10.5194/acp-5-2935-2005, 2005.

Cozic, J., Mertes, S., Verheggen, B., Cziczo, D. J., Gallavardin, S. J., Walter, S., Baltensperger, U., and Weingartner, E.: Black carbon enrichment in atmospheric ice particle residuals observed in lower tropospheric mixed phase clouds, J. Geophys. Res.Atmos., 113, D15209, doi:10.1029/2007JD009266, 2008.

Crawford, I., Möhler, O., Schnaiter, M., Saathoff, H., Liu, D., McMeeking, G., Linke, C., Flynn, M., Bower, K. N., Connolly, P. J., Gallagher, M. W., and Coe, H.: Studies of propane flame soot acting as heterogeneous ice nuclei in conjunction with single particle soot photometer measurements, Atmos. Chem. Phys., 11, 9549-9561, doi:10.5194/acp-11-9549-2011, 2011.

DeMott, P. J., Chen, Y., Kreidenweis, S. M., Rogers, D. C., and Sherman, D. E.: Ice formation by black carbon particles, Geophys. Res. Lett., 26, 2429-2432, doi:10.1029/1999GL900580, 1999.

Friedman, B., Kulkarni, G., Beranek, J., Zelenyuk, A., Thornton, J. A., and Cziczo, D. J.: Ice nucleation and droplet formation by bare and coated soot particles, J. Geophys. Res.-Atmos., 116, 17203-17203, doi:10.1029/2011JD015999, 2011.

Gunthe, S. S., Rose, D., Su, H., Garland, R. M., Achtert, P., Nowak, A., Wiedensohler, A., Kuwata, M., Takegawa, N., Kondo, Y., Hu, M., Shao, M., Zhu, T., Andreae, M. O., and Pöschl, U.: Cloud condensation nuclei $(\mathrm{CCN})$ from fresh and aged air pollution in the megacity region of Beijing, Atmos. Chem. Phys., 11, 1102311039, doi:10.5194/acp-11-11023-2011, 2011.

Herzog, M., Weisenstein, D. K., and Penner, J. E.: A dynamic aerosol module for global chemical transport models: Model description, J. Geophysical Res.-Atmos., 109, D18202, doi:10.1029/2003jd004405, 2004.

Hoose, C., Lohmann, U., Bennartz, R., Croft, B., and Lesins, G.: Global simulations of aerosol processing in clouds, Atmos. Chem. Phys., 8, 6939-6963, doi:10.5194/acp-8-6939-2008, 2008.

Kärcher, B., Möhler, O., DeMott, P. J., Pechtl, S., and Yu, F.: Insights into the role of soot aerosols in cirrus cloud formation, Atmos. Chem. Phys., 7, 4203-4227, doi:10.5194/acp-7-4203-2007, 2007.

Koch, D., Schulz, M., Kinne, S., McNaughton, C., Spackman, J. R., Balkanski, Y., Bauer, S., Berntsen, T., Bond, T. C., Boucher, O., Chin, M., Clarke, A., De Luca, N., Dentener, F., Diehl, T., Dubovik, O., Easter, R., Fahey, D. W., Feichter, J., Fillmore, D., Freitag, S., Ghan, S., Ginoux, P., Gong, S., Horowitz, L., Iversen, T., Kirkevåg, A., Klimont, Z., Kondo, Y., Krol, M., Liu, X., Miller, R., Montanaro, V., Moteki, N., Myhre, G., Penner, J. E., Perlwitz, J., Pitari, G., Reddy, S., Sahu, L., Sakamoto, H.,
Schuster, G., Schwarz, J. P., Seland, Ø., Stier, P., Takegawa, N., Takemura, T., Textor, C., van Aardenne, J. A., and Zhao, Y.: Evaluation of black carbon estimations in global aerosol models, Atmos. Chem. Phys., 9, 9001-9026, doi:10.5194/acp-9-9001-2009, 2009.

Koehler, K. A., DeMott, P. J., Kreidenweis, S. M., Popovicheva, O. B., Petters, M. D., Carrico, C. M., Kireeva, E. D., Khokhlova, T. D., and Shonija, N. K.:Cloud condensation nuclei and ice nucleation activity of hydrophobic and hydrophilic soot particles, Phys. Chem. Chem. Phys., 11, 7906- 7920, 2009.

Lin, G., Penner, J. E., Sillman, S., Taraborrelli, D., and Lelieveld, J.: Global modeling of SOA formation from dicarbonyls, epoxides, organic nitrates and peroxides, Atmos. Chem. Phys., 12, 47434774, doi:10.5194/acp-12-4743-2012, 2012.

Liu, X. H., Penner, J. E., and Herzog, M.: Global modeling of aerosol dynamics: Model description, evaluation, and interactions between sulfate and nonsulfate aerosols, J. Geophys. Res.Atmos., 110, D18206, doi:10.1029/2004JD005674, 2005.

Lohmann, U. and Hoose, C.: Sensitivity studies of different aerosol indirect effects in mixed-phase clouds, Atmos. Chem. Phys., 9, 8917-8934, doi:10.5194/acp-9-8917-2009, 2009.

Mohler, O., et al.: Effect of sulfuric acid coating on heterogeneous ice nucleation by soot aerosol particles, J. Geophys. Res.-Atmos., 110, D11210, doi:10.1029/2004JD005169, 2005.

Penner, J. E., Chuang, C. C., and Grant, K.: Climate forcing by carbonaceous and sulfate aerosols, Clim. Dynam., 14, 839-851, 1998.

Penner, J. E., Chen, Y., Wang, M., and Liu, X.: Possible influence of anthropogenic aerosols on cirrus clouds and anthropogenic forcing, Atmos. Chem. Phys., 9, 879-896, doi:10.5194/acp-9-8792009, 2009.

Petters, M. D. and Kreidenweis, S. M.: A single parameter representation of hygroscopic growth and cloud condensation nucleus activity, Atmos. Chem. Phys., 7, 1961-1971, doi:10.5194/acp-71961-2007, 2007.

Phillips, V. T. J., DeMott, P. J., and Andronache, C.: An empirical parameterization of heterogeneous ice nucleation for multiple chemical species of aerosol, J. Atmos. Sci., 65, 2757-2783, 2008.

Phillips, V. T. J., Demott, P. J., Andronache, C., Pratt, K. A., Prather, K. A., Subramanian, R., and Twohy, C.: Improvements to an Empirical Parameterization of Heterogeneous Ice Nucleation and Its Comparison with Observations, J. Atmos. Sci., 70, 378-409, doi:10.1175/jas-d-12-080.1, 2013.

Popovicheva, O., Persiantseva, N., Shonija, N., DeMott, P., Koehler, K., Petters, M., Kreidenweis, S., Tishkova, V., Demirdjian, B., and Suzanne, J.: Water interaction with hydrophobic and hydrophilic soot particles, Phys. Chem. Chem. Phys., 10, 23322344, 2008a.

Popovicheva, O. B., Persiantseva, N. M., Tishkova, V., Shonija, N. K., and Zubareva, N. A.: Quantification of water uptake by soot particles, Environ. Res. Lett., 3, 025009, doi:10.1088/17489326/3/2/025009, 2008b.

Popovicheva, O. B., Kireeva, E. D., Timofeev, M. A., Shonija, N. K., and Mogil'nikov, V. P.: Carbonaceous aerosols of aviation and shipping emissions, Izvestiya Atmos. Ocean. Phys., 46, 339346, 2010.

Popovicheva, O. B., Persiantseva, N. M., Kireeva, E. D., Khokhlova, T. D., and Shonija, N. K.: Quantification of the Hygroscopic Ef- 
fect of Soot Aging in the Atmosphere: Laboratory Simulations, J. Phys. Chem. A, 115, 298-306, 2011.

Pöschl, U., Canagaratna, M., Jayne, J. T., Molina, L. T., Worsnop, D. R., Kolb, C. E., and Molina, M. J.: Mass accommodation coefficient of $\mathrm{H}_{(2)} \mathrm{SO}_{(4)}$ vapor on aqueous sulfuric acid surfaces and gaseous diffusion coefficient of $\mathrm{H}_{(2)} \mathrm{SO}_{(4)}$ in $\mathrm{N}_{(2)} / \mathrm{H}_{(2)} \mathrm{O}, \mathrm{J}$. Phys. Chem. A, 102, 10082-10089, 1998.

Prenni, A. J., DeMott, P. J., Sullivan, A. P., Sullivan, R. C., Kreidenweis, S. M., and Rogers, D. C.: Biomass burning as a potential source for atmospheric ice nuclei: Western wildfires and prescribed burns, Geophys. Res. Lett., 39, L11805, doi:10.1029/2012g1051915, 2012.

Schwarz, J. P., Spackman, J. R., Fahey, D. W., Gao, R. S., Lohmann, U., Stier, P., Watts, L. A., Thomson, D. S., Lack, D. A., Pfister, L., Mahoney, M. J., Baumgardner, D., Wilson, J. C., and Reeves, J. M.: Coatings and their enhancement of black carbon light absorption in the tropical atmosphere, J. Geophys. Res., 113, D03203, doi:10.1029/2007JD009042, 2008.

Storelvmo, T., Kristjansson, J. E., and Lohmann, U.: Aerosol influence on mixed-phase clouds in CAM-Oslo, J. Atmos. Sci., 65, 3214-3230, 2008a.

Storelvmo, T., Kristjansson, J. E., Lohmann, U., Iversen, T., Kirkevåg, A., and Seland, O.: Modeling of the WegenerBergeron-Findeisen process-implications for aerosol indirect effects, Environ. Res. Lett., 3, 45001-45001, 2008 b.
Storelvmo, T., Hoose, C., and Eriksson, P.: Global modeling of mixed-phase clouds: The albedo and lifetime effects of aerosols, J. Geophys. Res.-Atmos., 116, 5207-5207, doi:10.1029/2010JD014724, 2011.

Wang, M. and Penner, J. E.: Cirrus clouds in a global climate model with a statistical cirrus cloud scheme, Atmos. Chem. Phys., 10, 5449-5474, doi:10.5194/acp-10-5449-2010, 2010.

Wang, M. H., Penner, J. E., and Liu, X. H.: Coupled IMPACT aerosol and NCAR CAM3 model: Evaluation of predicted aerosol number and size distribution, J. Geophys. Res.-Atmos., 114, D06302, doi:10.1029/2008JD010459, 2009.

Young, K. C.: Numerical-simulation of wintertime, orographic precipitation -1 . Description of model microphysics and numerical techniques, J. Atmos. Sci., 31, 1735-1748, 1974.

Yun, Y. and Penner, J. E.: Global model comparison of heterogeneous ice nucleation parameterizations in mixed phase clouds, J. Geophys. Res.-Atmos., 117, 7203-7203, doi:10.1029/2011JD016506, 2012.

Zhang, D. and Zhang, R. Y.: Laboratory investigation of heterogeneous interaction of sulfuric acid with soot, Environ. Sci. Technol., 39, 5722-5728, 2005.

Zhang, R. Y., Khalizov, A. F., Pagels, J., Zhang, D., Xue, H. X., and McMurry, P. H.: Variability in morphology, hygroscopicity, and optical properties of soot aerosols during atmospheric processing, Proc. Natl. Acad. Sci. USA, 105, 10291-10296, 2008. 